\title{
The link between transcript regulation and de novo protein synthesis in the retrograde high light acclimation response of Arabidopsis thaliana
}

\author{
Marie-Luise Oelze ${ }^{\dagger}$, Meenakumari Muthuramalingam ${ }^{\dagger}$, Marc Oliver Vogel and Karl-Josef Dietz
}

\begin{abstract}
Background: Efficient light acclimation of photosynthetic cells is a basic and important property of plants. The process of acclimation depends on transformation of retrograde signals in gene expression, transcript accumulation and de novo protein synthesis. While signalling cues, transcriptomes and some involved players have been characterized, an integrated view is only slowly emerging, and information on the translational level is missing. Transfer of low $\left(8 \mu \mathrm{mol}\right.$ quanta $\left.\mathrm{m}^{-2} \mathrm{~s}^{-1}\right)$ or normal light $\left(80 \mu \mathrm{mol}\right.$ quanta $\left.\mathrm{m}^{-2} \mathrm{~s}^{-1}\right)$ acclimated $30 \mathrm{~d}$ old Arabidopsis thaliana plants to high light $\left(800 \mu \mathrm{mol}\right.$ quanta $\left.\mathrm{m}^{-2} \cdot \mathrm{s}^{-1}\right)$ triggers retrograde signals. Using this established approach, we sought to link transcriptome data with de novo synthesized proteins by in vivo labelling with ${ }^{35} \mathrm{~S}$ methionine and proteome composition.
\end{abstract}

Results: De novo synthesized protein and proteome patterns could reliably be matched with newly annotated master gels. Each molecular level could be quantified for a set of 41 proteins. Among the proteins preferentially synthesized in plants transferred to high light were enzymes including carbonic anhydrase, fructose-1,6-bisphosphate aldolase, O-acetyl serine thiol lyase, and chaperones, while low rates upon transfer to high light were measured for e.g. dehydroascorbate reductase, glyceraldehyde-3-phosphate dehydrogenase and CuZn superoxide dismutase, and opposite responses between 10-fold and 100-fold light increment for e.g. glutamine synthetase and phosphoglycerate kinase.

Conclusions: The results prove the hypothesis that transcript abundance is poorly linked to de novo protein synthesis due to profound regulation at the level of translation. This vertical systems biology approach enables to quantitatively and kinetically link the molecular levels for scrutinizing signal processing and response generation.

\section{Background}

Fluctuating environmental conditions elicit acclimation responses that occur at different molecular levels and on various time scales. For immediate response to light intensity shifts the acclimation includes rapid posttranslational modifications such as reversible protein phosphorylation for state transition or photochemical quenching, and thioldisulfide transitions of metabolic enzymes [1]. An intermediate response to alter the proteome is mediated by modification of the transcripts recruited to the ribosomes and allows for fast adjustment of de novo synthesized proteins [2]. Initiated at the same time scale, transcriptional activity is adjusted, but due to the multiple subsequent

\footnotetext{
*Correspondence: karl-josef.dietz@uni-bielefeld.de

${ }^{\dagger}$ Equal contributors

Biochemistry and Physiology of Plants, Faculty of Biology - W5-134, University of Bielefeld, 33501 Bielefeld, Germany
} \\ C Biomed Central}

steps of transcript accumulation, translation and assembly, the response is somewhat delayed compared to the first and second mechanism [3]. Each level of molecular response is subjected to additional regulation such as RNA stability [4] and dynamics and assembly of complexes [5]. Since these reactions occur outside the organelles for most plastidic proteins their initiation and control depends on retrograde signals from the chloroplast. On a longer time scale reorganization of cell structures, epigenetic control of gene activity and changes in morphology realize additional levels of acclimatory modifications.

This work aims for understanding the different levels of molecular acclimation to high light (H-light). Arabidopsis thaliana has been repeatedly used to investigate reactions to H-light. Retrograde signals released within the chloroplast trigger signal transduction pathways that transmit information to the nucleus to modify gene expression 
necessary for acclimation. The origin and nature of plastid retrograde signals has been deduced from physiological and genetic experiments. Oxidation of the plastoquinone (PQ) pool activates the expression of chlorophyll-a/b-binding protein genes in the nucleus [6]. Redox changes in the intersystem electron transport chain as experimentally induced by preferential excitation of either photosystem II or photosystem I using light quality variation or by addition of inhibitors affect plastid and nuclear gene expression [7]. The thylakoid-associated protein kinases STN7 and STN8 mediate PQ-dependent regulation in the chloroplast, e.g. photosystem II protein phosphorylation, and in the long term response [8]. Signals originating downstream of photosystem I trigger the acclimation responses in chloroplasts and extrachloroplast compartments, e.g. regulating the expression of nuclear encoded 2-Cys peroxiredoxin [9]. Hormonal signals involved in retrograde signalling include abscisic acid, salicylic acid and 12-oxophytodienoic acid, the precursor of jasmonic acid [10-12]. In some cases signalling components such as transcription factors of the AP2/EREBP family participate in the retrograde signalling response. Few involved signalling elements could already tentatively be aligned. Thus, different operational signals from the chloroplast converge upstream of GUN1 and initiate ABI4-dependent nuclear gene expression [13]. Using genetic approaches, singlet oxygen signalling was associated with FLU and the functional executer isoforms EXE1 and EXE2 [14].

The here employed experimental design uses a differential light acclimation regime of Arabidopsis thaliana grown at low light near the light compensation point (about $8 \mu \mathrm{mol}$ quanta $\mathrm{m}^{-2} \mathrm{~s}^{-1}$ ) and normal growth light $\left(80 \mu \mathrm{mol}\right.$ quanta $\left.\mathrm{m}^{-2} \mathrm{~s}^{-1}\right)$ with a subsequent transfer to $\mathrm{H}$-light $\left(800 \mu \mathrm{mol}\right.$ quanta $\left.\mathrm{m}^{-2} \cdot \mathrm{s}^{-1}\right)$ as introduced before [11]. In the previous work transcript, protein and metabolite levels, as wells as activities of components of the water-water cycle were compared with untreated control plants at $6 \mathrm{~h}$ and $24 \mathrm{~h}$ after the 10- and 100-fold light shift. In addition the response of marker transcripts described as suitable indicators for sugar, $\mathrm{ABA}$, plastoquinone, singlet oxygen, ROS, lipid and overreduction-dependent signalling was determined in that study, suggesting a major signalling function for reductive power, metabolites, and lipids. Strong transcript regulation for water-water cycle enzymes, e.g. stromal and thylakoid-bound ascorbate peroxidases, dehydroascorbate reductase and $\mathrm{CuZn}$-superoxide dismutase, was not reflected at the protein level [11]. This prompted us to ask whether the transcriptional regulation translates into increased protein synthesis.

Few methods allow for analysis of the de novo protein synthesis. Among these are the expression of protein $\mathrm{fu}-$ sions with reporters that are detectable in vivo or ex vivo using endogenous promoters [15], the use of translation inhibitors such as cycloheximide to follow the decline in protein amount and assuming that the difference relative to the non-inhibited conditions represents the contribution of de novo protein synthesis [16]. However, the only direct method aims at labelling the de novo synthesized protein by incorporation of isotopes which either can be determined mass spectrometrically [17] or in case of radioactive elements can be followed by scintillation counting of immunoprecipitates or autoradiography following 2D separations [18]. Increasing sensitivity, dual labelling methods and quantitative spectral counting in mass spectrometric analysis also give access to de novo synthesized proteins if sufficient proportions of the stable isotope are incorporated $[17,19]$. At present the sensitivity and broad applicability of radiolabelling to biological samples followed by 2D separation still offers a competitive alternative in a zero background.

Many studies on retrograde signalling from the chloroplast to the nucleus focused on transcript regulation as easy readout and on genetic approaches to identify disturbances. Here we wanted to learn more on retrograde signalling in response to a strong light intensity shift with focus on de novo synthesized proteins. Labelling of de novo synthesized proteins often coupled to immunoprecipitation has been and is a broadly used method. However, attempts appear to be missing to use this strong technology in the systems biology era. Therefore, we aimed for exploring the potential of using 35S-methionine labelling to assess the coupling between retrograde signalling-induced changes in transcript levels to de novo protein synthesis and protein levels.

\section{Results}

Low (L-) and normal (N-) light-acclimated plants were transferred to the same high (H-) light intensity of $800 \mu \mathrm{mol}$ quanta $\mathrm{m}^{-2} \mathrm{~s}^{-1}$ which is equivalent to a 100- and 10-fold increase over acclimation light, respectively. The experimental design and the response of the plants have been described in detail by Oelze et al. [11]. Table 1 summarizes four parameters measured as basic parameters and taken from Oelze et al. [11]: It can be seen that the L-plants only had $38 \%$ of the fresh weight-related RNA of Nplants, $48 \%$ protein and $61 \%$ chlorophyll. Protein and RNA tented to increase during the H-treatment, however only in the $\mathrm{L} \rightarrow \mathrm{H}$-light treatment protein content increased significantly. Effective quantum yield of photosynthesis decreased significantly during the $\mathrm{H}$-light treatment, albeit less in the $\mathrm{N} \rightarrow \mathrm{H}$-plants than in the $\mathrm{L} \rightarrow \mathrm{H}$-plants. It should be noted that the photoinhibition was entirely reversible [11].

$\mathrm{H}$-light triggers the release of retrograde signals which derive from the chloroplast, modify nuclear gene expression and initiate acclimation responses. L- and $\mathrm{N}$-plants revealed 2.219 transcripts with $\geq 2$-fold difference. The transcriptional regulation following transfer to $\mathrm{H}$-light was almost 
Table 1 Basic characterization of plants grown in normal (N) or in low (L) light, or transferred to high (H) light for 6 h $(\mathbf{N} \rightarrow \mathbf{H}, \mathbf{L} \rightarrow \mathbf{H})$

\begin{tabular}{|c|c|c|c|c|}
\hline \multirow[t]{2}{*}{ Parameter } & \multicolumn{4}{|c|}{ Treatment } \\
\hline & $\mathbf{N}$ & $\mathrm{N} \rightarrow \mathrm{H}$ & $\mathbf{L}$ & $\mathrm{L} \rightarrow \mathrm{H}$ \\
\hline Chlorophyll [mg/g fw] & $1.22 \pm 0.10^{\mathrm{a}}$ & $1.15 \pm 0.10^{a}$ & $0.75 \pm 0.08^{b}$ & $0.80 \pm 0.10^{b}$ \\
\hline ФPSII [r.U.] & $0.76 \pm 0.01^{\mathrm{a}}$ & $0.62 \pm 0.04^{c}$ & $0.72 \pm 0.02^{b}$ & $0.49 \pm 0.05^{c}$ \\
\hline Protein [mg/g fw] & $10.19 \pm 1.01^{a}$ & $11.49 \pm 0.96^{a}$ & $4.94 \pm 0.14^{c}$ & $5.58 \pm 0.33^{b}$ \\
\hline RNA $[\mu \mathrm{g} / \mathrm{g} \mathrm{fw}]$ & $13.92 \pm 6.60^{\mathrm{a}}$ & $17.27 \pm 7.91^{\mathrm{a}}$ & $5.31 \pm 3.11^{b}$ & $5.89 \pm 3.02^{b}$ \\
\hline
\end{tabular}

Contents of chlorophyll, protein and RNA were determined in leaf samples ( $\mathrm{n}$ between 3 and 8 independent experiments, $\mathrm{m} \pm \mathrm{SD}$; different letters mark significance groups according to $t$-test, $\mathrm{p} \leq 0.05$ ). Effective quantum yield of photosystem II as measured by pulse amplitude modulated chlorophyll fluorimetry is shown as $m \pm S D$ with $n=30$ from 3 independent experiments. Letters mark groups of significant difference according to $t$-test, with $p \leq 0.01$. Data are from [11].

finished after $6 \mathrm{~h}$, with only 205 transcripts remaining differentially expressed between $\mathrm{L} \rightarrow \mathrm{H}$ - and $\mathrm{N} \rightarrow \mathrm{H}$-plants [20]. This experimental system has previously been established in order to follow the acclimation process to $\mathrm{H}$-light in particular with focus on the antioxidant defence system after $6 \mathrm{~h}$ of H-light exposure [11] and to address involved signalling pathways in a time-resolved manner [20]. The setup appeared suitable to ask the next question concerning the coupling between transcript regulation and de novo protein synthesis. To this end leaf proteins were extracted from L-, $\mathrm{N}-, \mathrm{L} \rightarrow \mathrm{H}$ - and $\mathrm{N} \rightarrow \mathrm{H}$-light samples after $6 \mathrm{~h}$ of treatment and subjected to 2D gel electrophoresis with silver staining for sensitive visualization of protein pattern (Figure 1). Polypeptides were excised from parallel gels and subjected to mass spectrometric identification (Table 2). Using this information and 2D analysis software a partially annotated master gel was assembled (Figure 2).

In the next step, radioactively labelled 35S-methionine was applied to leaf surfaces of intact plants in the identical experimental setup at $1 \mathrm{pm}$, i.e. $4 \mathrm{~h}$ after the beginning of $\mathrm{H}$-treatment, and the plants were further incubated for two more hours. Thus, harvesting and analysis of de novo synthesized proteins occurred $6 \mathrm{~h}$ after transfer to H-light. For analysis protein extracts of labelled leaves equivalent to $10^{6}$ counts per minute were subjected to 2D PAGE and analysed by autoradiography (Figure 3 ). The four conditions resembled each other in the basic pattern of a large set of proteins, but also revealed significant differences,

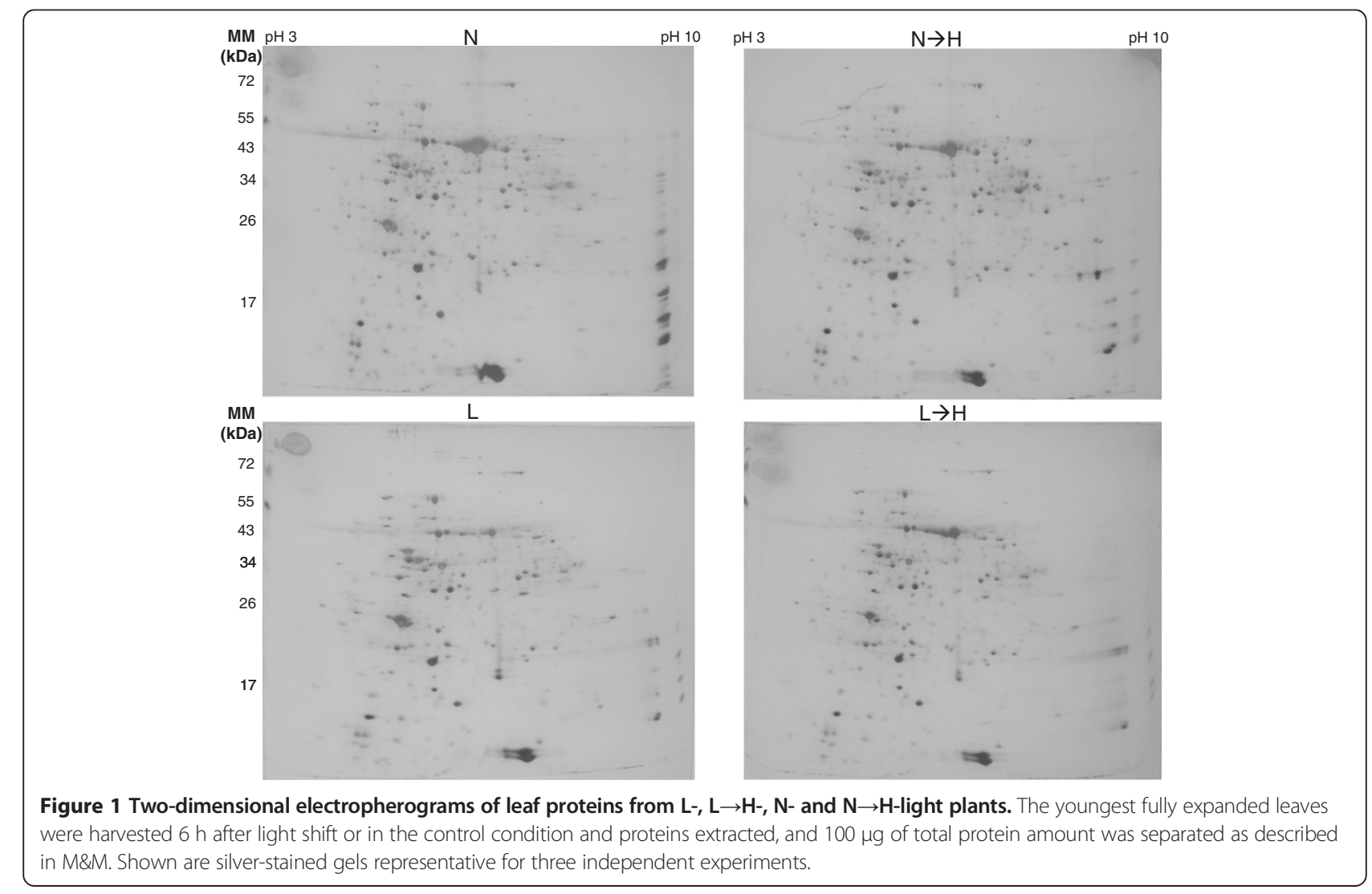


Table 2 Compilation of polypeptides identified both in the silver stained gels and in the autoradiogram

\begin{tabular}{|c|c|c|c|c|c|c|c|c|}
\hline & Protein name & ATG number & MM (kDa) & Localization & Functional role & Silver & De novo & Mascot score \\
\hline 1. & 2-Cys Peroxiredoxin & AT3G11630 & 22.4 & Chloroplast & Defense response & + & + & 66 \\
\hline 2. & 3-Ketoacyl CoA thiolase 3 & AT2G33150 & 48.6 & Peroxisome & Fatty acid biosynthesis & + & + & 99 \\
\hline 3 & Ascorbate peroxidase 1 & AT1G07890 & 27.6 & Cytosol & Defense response & + & + & 253 \\
\hline 4. & ATP synthase delta-subunit & AT4G09650 & 22.8 & Chloroplast & ATP synthesis & + & + & 260 \\
\hline 5. & ATP synthase subunit beta & ATCG00480 & 47.7 & Chloroplast & ATP synthesis & + & + & 365 \\
\hline 6. & Carbonic anhydrase 1 & AT3G01500 & 25.6 & Chloroplast & Carbon utilization & + & + & 45 \\
\hline 7. & Carbonic anhydrase 2 & AT5G14740 & 25.1 & Chloroplast & Carbon utilization & + & + & 72 \\
\hline 8. & Chaperonin 60 beta & AT1G55490 & 58.1 & Chloroplast & Protein folding & + & + & 89 \\
\hline 9. & Chloroplast HSP 70-1 & AT4G24280 & 74.6 & Chloroplast & Stress response & + & + & 528 \\
\hline 10. & Chloroplast HSP 70-2 & AT5G49910 & 74.6 & Chloroplast & Stress response & + & + & 337 \\
\hline 11. & Cu/Zn Superoxide dismutase & AT2G28190 & 15.7 & Chloroplast & Defense response & + & + & 81 \\
\hline 12. & Cyclophilin Cyp 20-3 & AT3G62030 & 19.7 & Chloroplast & Rotamase & + & + & 207 \\
\hline 13. & Dehydroascorbate reductase & AT1G19570 & 21.7 & Cytosolic & Defense response & + & + & 93 \\
\hline 14. & D-Ribulose-5-P epimerase & AT5G61410 & 28 & Chloroplast & Calvin cycle & + & ND & 154 \\
\hline 15. & Fructose-bisphosphate aldolase 1 & AT2G21330 & 41.9 & Chloroplast & Calvin cycle & + & + & 91 \\
\hline 16. & Fructose-bisphosphate aldolase 2 & AT4G38970 & 38 & Chloroplast & Calvin cycle & + & + & 106 \\
\hline 17. & GAP C2 subunit & AT1G13440 & 36.9 & Cytosol & Oxidoreductase & + & + & 164 \\
\hline 18. & Germin 3 oxalate oxidase & AT5G20630 & 19.5 & Apoplast & Defense response & + & ND & 243 \\
\hline 19. & Glutamine synthetase 2 & AT5G35630 & 42.5 & Chloro/Mito & Glutamine biosynthesis & + & + & 141 \\
\hline 20. & Glutathione S-transferase F8 & AT2G47730 & 23.9 & Chloroplast & Stress response & + & ND & 71 \\
\hline 21. & Glutathione S-transferase F9 & AT2G30860 & 24.2 & Cytosol & Stress response & + & ND & 118 \\
\hline 22. & Glyceraldehyde-3-P-DH, B subunit & AT1G42970 & 39.3 & Chloroplast & Calvin cycle & + & + & 70 \\
\hline 23. & HCF 136 & AT5G23120 & 38.5 & Chloroplast & Photosynthesis & + & + & 173 \\
\hline 24. & Lactate/malate dehydrogenase & AT1G53240 & 33.2 & Mitochond. & TCA-cycle & + & + & 65 \\
\hline 25. & Malate dehydrogenase & AT3G47520 & 34 & Chloroplast & Redox metabolism & + & + & 107 \\
\hline 26. & Manganese SOD & AT3G10920 & 22.2 & Mitochond & Defence response & + & ND & 78 \\
\hline 27. & O-Acetyl serine thiol lyase B & AT2G43750 & 35.1 & Chloroplast & Cysteine biosynthesis & + & + & 85 \\
\hline 28. & Phosphoglycerate kinase 1 & AT1G79550 & 42.63 & Chloroplast & Calvin cycle & + & + & 86 \\
\hline 29. & Phosphoglycerate mutase & AT3G08590 & 60.7 & Cytosol & Glycolysis & -+ & + & 143 \\
\hline 30. & Phosphoribulokinase & AT1G32060 & 39.2 & Chloroplast & Calvin cycle & + & + & 97 \\
\hline 31. & Plastid-lipid-associated protein 1 & AT4G04020 & 34.9 & Chloroplast & Stress response & + & + & 113 \\
\hline 32. & Plastocyanin (DRT 112) & AT1G20340 & 10.5 & Chloroplast & Electron transport & + & ND & 169 \\
\hline 33. & PSII oxygen evolving complex & AT5G66570 & 26.5 & Chloroplast & Photosynthesis & + & + & 114 \\
\hline 34. & PSII, subunit PSB-O2 & AT3G50820 & 35.0 & Chloroplast & Photosynthesis & + & + & 304 \\
\hline 35. & PSII subunit P-1 & AT1G06680 & 20.2 & Chloroplast & Photosynthesis & + & + & 183 \\
\hline 36. & Ribose 5-phosphate isomerase & AT3G04790 & 27.1 & Chloroplast & Calvin cycle & + & ND & 161 \\
\hline 37. & Ribosomal protein S1 & AT5G30510 & 40.5 & Chloroplast & RNA binding & + & + & 70 \\
\hline 38. & RPL12 | ribosomal protein L12-A & AT3G27830 & 14 & Chloroplast & Translation & + & + & 78 \\
\hline 39. & Rubisco activase & AT2G39730 & 46.2 & Chloroplast & Calvin cycle & + & + & 462 \\
\hline 40. & RubisCO large subunit & ATCG00490 & 53 & Chloroplast & Calvin cycle & + & + & 304 \\
\hline 41. & RubisCO small subunit $1 \mathrm{~A}$ & AT1G67090 & 14.7 & Chloroplast & Calvin cycle & + & + & 346 \\
\hline 42. & RubisCO small subunit $1 \mathrm{~B}$ & AT5G38430 & 14.8 & Chloroplast & Calvin cycle & + & + & 71 \\
\hline 43. & RubisCO small subunit 2B & AT5G38420 & 14.8 & Chloroplast & Calvin cycle & + & + & 308 \\
\hline 44. & S-Adenosylmethionine synthetase 1 & AT1G02500 & 43.2 & Cytoplasm & Met adenos.transferase & + & ND & 92 \\
\hline
\end{tabular}


Table 2 Compilation of polypeptides identified both in the silver stained gels and in the autoradiogram (Continued)

\begin{tabular}{|c|c|c|c|c|c|c|c|c|}
\hline 45. & Sedoheptulose-bisphosphatase & AT3G55800 & 36.1 & Chloroplast & Calvin cycle & + & + & 229 \\
\hline 46. & Stromal APx & AT4G08390 & 37.8 & Chloroplast & Defense response & + & + & 67 \\
\hline 47. & Thioredoxin m1 & AT1G03680 & 12.4 & Chloroplast & Defense response & + & + & 105 \\
\hline 48. & Thioredoxin m2 & AT4G03520 & 12.5 & Chloroplast & Defense response & + & + & 72 \\
\hline 49. & Triose phosphate isomerase & AT2G21170 & 27 & Chloroplast & Calvin cycle & + & + & 133 \\
\hline
\end{tabular}

Shown are the specific details about size, predicted localization, the functional role of the proteins and the MASCOT score. MG \#: number in annotated master gel; +: Unequivocally identified by mass spectrometry with at least two peptides; +-: tentatively identified by one peptide; ND: not detected. Polypeptides \#5 and 40 are plastome-encoded.

ND- not detected in autoradiograms.

particularly between $\mathrm{L}$ - and $\mathrm{L} \rightarrow \mathrm{H}$-plants on the one hand and $\mathrm{N}$ - and $\mathrm{N} \rightarrow \mathrm{H}$-plants on the other. The most obvious difference was monitored for RubisCO large subunit which was synthesized both in $\mathrm{N}$ - and $\mathrm{N} \rightarrow \mathrm{H}$-plants at high rates, but label was almost absent in L-plants and only slightly induced in L-plants upon transfer to $\mathrm{H}$-light. All gels from the three independent experiments were matched to generate a fused master gel image utilizing Delta 2D software (Figure 4) and analyzed for spot response behaviour. In total 129 spots could be identified that revealed differences among the treatments with statistical significance $<0.01$ (one way ANOVA). The clustered heat map for three experiments with 12 samples and 129 significantly altered spots is depicted in Figure 4B. It shows (a) a consistent regulation for same treatments in the three independent experiments, (b) the contrasting regulatory state of Lplants compared to that of all other treatments, and (c) the efficiency of $\mathrm{L} \rightarrow \mathrm{H}$-plants in adjusting the pattern of de novo synthesized proteins to that of $\mathrm{N} \rightarrow \mathrm{H}$-plants despite the different starting points. Four major cluster types of regulation could be identified: Polypeptides of cluster 1 were synthesized at low de novo rates in $\mathrm{N} \rightarrow \mathrm{H}$ - and $\mathrm{L} \rightarrow \mathrm{H}$-plants, polypeptides of cluster 2 were high in $\mathrm{N} \rightarrow \mathrm{H}-$ and $\mathrm{L} \rightarrow \mathrm{H}$-plants. Cluster 3 includes polypeptides whose synthesis showed contrasting responses in $\mathrm{H}$-light, i.e. stimulation in $\mathrm{N} \rightarrow \mathrm{H}$ and low synthesis in $\mathrm{L} \rightarrow \mathrm{H}$-plants, while cluster 4 showed the opposite. Focussing on proteins being synthesized above ('up-regulated') or below average allowed the generation of a Venndiagram (Figure 4C), that confirmed the impression from the heat map, namely that the labelling pattern of $\mathrm{N}$-plants was most closely related to the average state with only 26 spots (20\%) synthesized above or below average of all treatments, 9 of which were specific to N-plant, 12 overlapped with L-plants and 5 with $\mathrm{N} \rightarrow \mathrm{H}$-plants. Radiolabel of $50 \%(=64)$ of the spots in L-plants deviated from average; 47 being specific and only 5 were present in a distinct amount after transfer to $\mathrm{H}$-light. Levels in $22 \%$ (28) spots deviated from average in $\mathrm{N} \rightarrow \mathrm{H}$ and $\mathrm{L} \rightarrow \mathrm{H}$-plants.

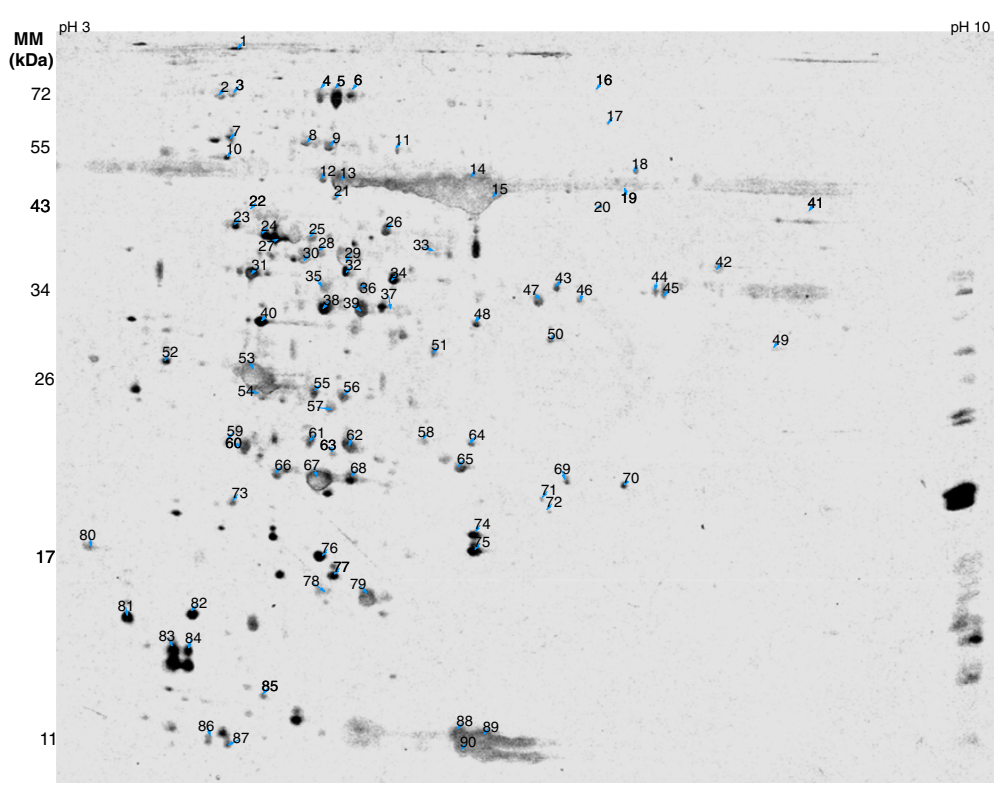

Figure 2 Annotated reference gel ('master gel') for the light shift experiment. $100 \mathrm{\mu g}$ of total protein was separated by 2D gel electrophoresis. Spots were excised and 90 polypeptides were identified by mass spectrometric analysis. 


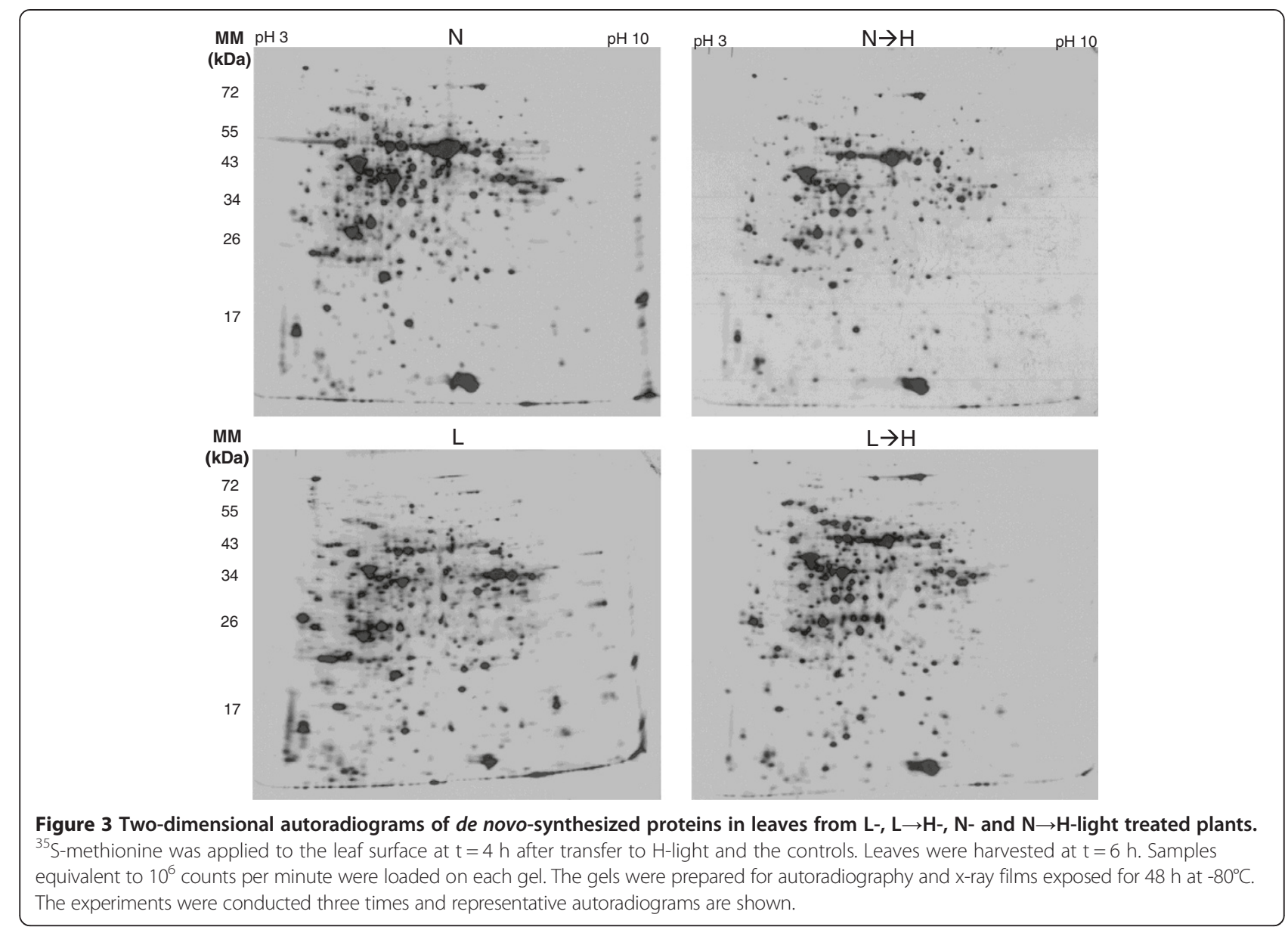

(A)

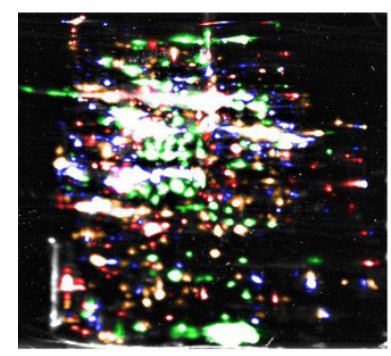

(C)

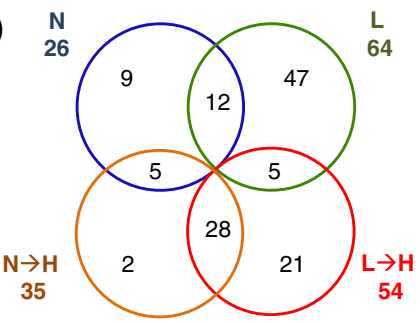

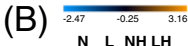

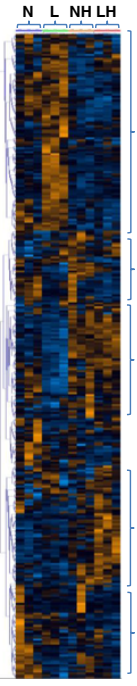

Cluster 1: $\mathrm{L} \rightarrow \mathrm{H}$ and $\mathrm{N} \rightarrow \mathrm{H}$ low

Cluster 3: $\mathrm{N} \rightarrow \mathrm{H}$ high and $\mathrm{L} \rightarrow \mathrm{H}$ low

Cluster 2: $\mathrm{N} \rightarrow \mathrm{H}$ high and $\mathrm{L} \rightarrow \mathrm{H}$ high

Cluster 2: $\mathrm{N} \rightarrow \mathrm{H}$ high and $\mathrm{L} \rightarrow \mathrm{H}$ high

Cluster 4: $\mathrm{L}$ and $\mathrm{L} \rightarrow \mathrm{H}$ low

Figure 4 Analysis of the autoradiograms for changes in reliably detected de novo synthesized proteins. Three autoradiograms for each condition from independent experiments were analysed with the Delta 2D software. (A) The results from three gels were fused and spots color-coded: $\mathrm{N}=$ blue, $\mathrm{N} \rightarrow \mathrm{H}=$ orange, $\mathrm{L}=$ green, $\mathrm{L} \rightarrow \mathrm{H}=$ red. (B) A heat map was automatically constructed as described above based on the set of 129 reliably detected changes that were classified as significant with one way ANOVA ( $p \leq 0.01)$. The lanes of the three identical conditions were placed next to each other. The four clusters were categorized according to the automatically generated cluster tree depicted on the left hand side. (C) Venn diagram of the significantly up-regulated spot intensities representing the overlaps among treatments. 
Autoradiographs were digitalized and the spot landscape warped to the master gel image. The protein pattern of de novo synthesized and, thus, radiolabelled polypeptides differed considerably from silver- or Coomassiestained 2D patterns (Figures 1, 2 and 3). Despite these differences, both patterns could reliably be matched since many spots served as unambiguous landmarks. In the next step all 12 gels from four conditions with three experiments were matched, the spot volume as well the greyness quantified and the annotated polypeptides were confirmed manually. The results of these 49 polypeptides are given in Table 2 which lists the AT number, molecular mass, localization, detection in the silver stained gels or autoradiograms and the MASCOT score. Eight polypeptides detected in the annotated gels were not found in the autoradiograms. The vast majority of polypeptides, namely $80 \%$ showed a proven or predicted chloroplast localisation. De novo protein synthesis of these proteins was investigated for its response to the treatment and assigned to the four major response clusters (Table 3). In cluster 1 "change in de novo protein synthesis down in both $\mathrm{H}$-treatments" appeared polypeptides with function in photosynthetic electron transport and antioxidant defence. Chaperones and proteins of redox homeostasis were found in cluster 2 "up in both H-treatment". Metabolic enzymes predominated cluster 3 "up in $\mathrm{N} \rightarrow \mathrm{H}$ and down in $\mathrm{L} \rightarrow \mathrm{H}$-plants", and cluster 4 " $\mathrm{N}$ and $\mathrm{N} \rightarrow \mathrm{H}$ low" with ascorbate peroxidases and redox regulatory elements such as cyclophilin Cyp20-3 and malate dehydrogenase.

As reported before, RNA was isolated from leaves treated as above ( $\mathrm{L}-, \mathrm{N}-, \mathrm{L} \rightarrow \mathrm{H}, \mathrm{N} \rightarrow \mathrm{H})$ at $\mathrm{t}=6 \mathrm{~h}$. ATH1 whole genome arrays were hybridized from three experiments [20]. Raw data were processed with ROBIN (MPI Golm, Germany) and normalized on total intensity of all spots (RMA normalisation [21]. Means and corrected standard error $(\mathrm{p}<0.005)$ were calculated $[22,23]$. Transcripts identified in the autoradiograms and silver stained gels were selected from the list of transcripts and ratios of change were calculated. Figure 5 summarizes the results for the protein, de novo-synthesized and transcript level by heat map representation. Total protein was unrelated to transcript levels and de novo protein synthesis rates. However, also changes in transcript levels were unrelated to de novo synthesis for most genes. The changes upon the 10- and 100 -fold light shift in transcript amounts were related to the changes in de novo protein synthesis and plotted in a diagram (Figure 6).

\section{Discussion}

\section{Reorganization of the leaf proteome in light acclimation}

Sun and shade acclimation depends on structural and functional reorganization of photosynthetic organs [24,25]. Total leaf protein amount related to fresh weight differed between plants grown under L- or N-light conditions more than twofold. Two possible reasons might exist, namely either a similar protein complement at lower level or a profound qualitative difference that explains the lower level. Since plasmatic compartments such as cytosol, matrix and stroma contain about $25 \%(\mathrm{w} / \mathrm{v})$ protein, e.g. $10 \mathrm{mg}$ protein $/ 40 \mu \mathrm{l}$ chloroplast volume [26,27], a twofold difference clearly indicates that the volumes of plasmatic compartments is strongly decreased after the $10 \mathrm{~d}$ L-light acclimation [11]. But in addition to a general decrease in volume, polypeptide composition also changes qualitatively. The best established example of light acclimationdependent differences in protein composition concerns the increase in D1 protein and the decrease in light harvesting complex proteins (LHCII) with increasing growth light [28]. Changes in the photosynthetic apparatus are instrumental to adjust energy conversion and growth and are also important for optimized resource allocation, e.g. in dependence on light and nitrogen availability [29]. Protein patterns of silver-stained electropherograms differed between L- and N-acclimated plants. Many polypeptides appeared to be less abundant in N-light plants than in L-plants. This may be explained by normalization of each spot on total intensities in the gels. Due to the high RubisCO amount in extracts from N-plants, the intensities of most other bands will appear to be lower. But considering the low fresh weight-related protein contents of L-plants it becomes clear that the polypeptide abundance in silver gels would need some correction if polypeptide abundance should be related to fresh weight. Abundance of only few proteins changed during the $6 \mathrm{~h}$ period of $\mathrm{H}$-light treatment. RubisCO was among the significantly accumulating proteins in the $\mathrm{L} \rightarrow \mathrm{H}$-plants. It should be noted that the combined evaluation of both light shift treatments appeared justified despite in some cases different starting points due to the mostly similar response of protein abundance (82\% similar response) and transcript regulation (100\% similar response). This regulation leads to a highly similar transcriptome state after $6 \mathrm{~h}$ H-light [20].

\section{Strengths and drawbacks of in vivo labelling of de novo synthesized proteins}

Acclimation responses to environmental conditions are most frequently analysed at the level of specific transcripts or of genome-wide transcriptomes [30]. The matching of annotated silver-stained or Coomassie-stained 2D gels with autoradiograms was expected to allow for protein assignments of de novo synthesized polypeptides. But the labelling method needs some discussion. Labelling of intact plant tissue with ${ }^{35} \mathrm{~S}$-methionine requires time for uptake and incorporation, and in some studies it was achieved by wounding [31], in others by feeding via the transpiration stream [18] or by application to tissue surfaces. We chose the application to the cuticular surface of the 
Table 3 Clustering of de novo synthesized proteins with identified functional assignment

\begin{tabular}{|c|c|c|c|}
\hline Cluster & Response pattern & Transcripts/genes & Functional role \\
\hline \multirow[t]{8}{*}{1} & $\mathrm{~L} \rightarrow \mathrm{H} \& \mathrm{~N} \rightarrow \mathrm{H}$ low & DHAR & Antioxidant defence \\
\hline & & GAPDH B subunit & Photosynthesis \\
\hline & & PSII subunit O-2 & Photosynthesis \\
\hline & & PSII subunit P-1 & Photosynthesis \\
\hline & & Ribose 5-P isomerase A & Photosynthesis \\
\hline & & RPL12, ribosomal protein & Protein synthesis \\
\hline & & $\mathrm{SOD}, \mathrm{Cu} / \mathrm{Zn}$ & Antioxidant defence \\
\hline & & Thioredoxin m2 & Redox regulation \\
\hline \multirow[t]{8}{*}{2} & $\mathrm{~L} \rightarrow \mathrm{H} \& \mathrm{~N} \rightarrow \mathrm{H}$ high & Carbonic anhydrase 2 & Photosynthesis \\
\hline & & Chaperonin 60 beta & Protein folding \\
\hline & & FBP aldolase1 & Photosynthesis \\
\hline & & FBP aldolase 2 & Photosynthesis \\
\hline & & HCF 136 & Photosynthesis \\
\hline & & HSP 70-1, cp & Stress response \\
\hline & & Lactate/malate DH & Respiration \\
\hline & & O-Acetyl serine thiol lyase B & Sulfur metabolism \\
\hline \multirow[t]{10}{*}{3} & $\mathrm{~N} \rightarrow \mathrm{H}$ high, $\mathrm{L} \rightarrow \mathrm{H}$ low & 3-Ketoacyl CoA thiolase 3 & Fatty acid metabolism \\
\hline & & GAP C2 subunit & Photosynthesis \\
\hline & & Glutamine synthetase 2 & Nitrogen metabolism \\
\hline & & Phosphoglycerate kinase 1 & Photosynthesis \\
\hline & & Phosphoribulo kinase & Photosynthesis \\
\hline & & Rubisco activase & Photosynthesis \\
\hline & & Plastid-lipid-associated protein 1 & Stress response \\
\hline & & RubisCO SU 1A & Photosynthesis \\
\hline & & SBPase & Photosynthesis \\
\hline & & SAM synthetase 1 & Sulfur metabolism \\
\hline \multirow[t]{8}{*}{4} & $\mathrm{~N}, \mathrm{~N} \rightarrow \mathrm{H}$-high; L, L $\rightarrow$ H-low & ATP synthase beta & Photosynthesis \\
\hline & & ATP synthase delta & Photosynthesis \\
\hline & & APX 1 & Antioxidant defence \\
\hline & & APx, stromal, cp & Antioxidant defence \\
\hline & & Carbonic anhydrase 1 & Photosynthesis \\
\hline & & Cyclophilin Cyp 20-3 & Redox regulation \\
\hline & & Malate DH cyt & Redox regulation \\
\hline & & PSII OEC & Photosynthesis \\
\hline \multirow[t]{10}{*}{ No peculiar group pattern } & & 2-Cys Peroxiredoxin & Antioxidant defence \\
\hline & & Germin 3 oxalate oxidase & Stress defence \\
\hline & & GST F8 & Stress defence \\
\hline & & GST F9 & Stress defence \\
\hline & & HSP 70-2, cP & Stress defence \\
\hline & & Malate $\mathrm{DH}, \mathrm{cp}$ & Redox regulation \\
\hline & & Mn SOD & Antioxidant defence \\
\hline & & Phosphoglycerate mutase & Glycolysis \\
\hline & & Plastocyanin (DRT 112) & Photosynthesis \\
\hline & & Ribosomal protein S1 & Protein synthesis \\
\hline
\end{tabular}


Table 3 Clustering of de novo synthesized proteins with identified functional assignment (Continued)

\begin{tabular}{lll}
\hline & RubisCo large subunit & Photosynthesis \\
Photosynthesis & Ribulose-5-P epimerase & Redox regulation \\
\hline
\end{tabular}

The proteins were clustered using the Delta 2D-software package and assigned to four major types of regulation (Clusters 1 to 4 ) as outlined.

youngest fully expanded leaves because neither application to the transpiration stream e.g. by injection or wounding, appeared suitable for our purpose of undisturbed but sensitive labelling of newly synthesized proteins. Labelling de novo synthesized leaf proteins by feeding the labelled amino acid to roots unlikely would allow for sufficiently strong incorporation within $2 \mathrm{~h}$, but this could be compared in the future. The experimental design required incubation time for sufficient incorporation. Nevertheless, radiolabelling still is the only method at hand that allows for rapid, sensitive and reliable labelling of the de novo synthesized protein. It may be expected that with further advancement of mass

\begin{tabular}{|c|c|c|c|c|c|c|c|c|c|c|c|c|c|}
\hline \multirow[b]{2}{*}{ Tair-ID } & \multirow[b]{2}{*}{ Annotation } & \multicolumn{4}{|c|}{$\begin{array}{l}\text { Silver stained gels } \\
\text { relation of intensities }\end{array}$} & \multicolumn{4}{|c|}{$\begin{array}{l}\text { de novo protein synthesis } \\
\text { relation of intensities }\end{array}$} & \multicolumn{4}{|c|}{$\begin{array}{l}\text { transcript changes } \\
\text { relation of intensities }\end{array}$} \\
\hline & & $N / L$ & $\mathrm{~N} \rightarrow \mathrm{H}$ & $\mathrm{L} \rightarrow \mathrm{H}$ & $\mathrm{LH} / \mathrm{NH}$ & $N / L$ & $\mathrm{~N} \rightarrow>\mathrm{H}$ & $\mathrm{L} \rightarrow \mathrm{H}$ & $\mathrm{LH} / \mathrm{NH}$ & $N / L$ & $\mathrm{~N} \rightarrow \mathrm{H}$ & $\mathrm{L} \rightarrow \mathrm{H}$ & $\mathrm{LH} / \mathrm{NH}$ \\
\hline AT3G11630 & 2-Cys peroxiredoxin & $-1.0 *$ & 0.6 & -0.2 & $0.2 *$ & 0.5 & $0.9 *$ & 0.1 & $-1.3 *$ & $0.7 *$ & 0.2 & $0.6 *$ & -0.2 \\
\hline AT2G33150 & 3-Ketoacyl CoA thiolase 3 & -1.7 & $1.7 *$ & 0.0 & 0.0 & $-1.0 *$ & $-0.4 *$ & $-1.5 *$ & -0.2 & $-0.3 *$ & $-0.7 \star$ & $-1.1 \star$ & -0.2 \\
\hline AT4G09650 & ATP synthase, subunit delta & -0.7 & 0.5 & -0.3 & -0.2 & $1.9 *$ & -0.6 & $1.1 *$ & $-0.2 *$ & $1.9 *$ & 0.0 & $1.8 *$ & -0.2 \\
\hline ATCG00480 & ATP synthase, subunit beta & -1.0 & -0.7 & -0.2 & $1.5 *$ & 0.1 & 0.3 & $-0.4 *$ & $-0.9 *$ & 0.0 & 0.0 & -0.1 & -0.1 \\
\hline AT3G01500 & Carbonic anhydrase 1 & $0.4 *$ & 0.1 & 0.2 & $-0.3 *$ & $0.9 *$ & 0.1 & $0.6 *$ & $-0.4 *$ & $1.6 *$ & 0.5 & $2.0 *$ & 0.1 \\
\hline AT5G14740 & Carbonic anhydrase 2 & 0.2 & 0.8 & 0.0 & $-1.0 *$ & 0.4 & $1.2 *$ & $1.1 *$ & -0.5 & 0.1 & $0.4 *$ & $0.6 \star$ & 0.1 \\
\hline AT1G55490 & Chaperonin 60 beta & -2.2 & 1.9 & -0.1 & 0.3 & $1.7 *$ & $0.8 *$ & $3.1 *$ & 0.6 & $1.4 *$ & $1.3 *$ & $3.0 *$ & 0.3 \\
\hline AT4G24280 & Chloroplast HSP 70-1 & -0.5 & 0.4 & -0.2 & -0.1 & $1.1 *$ & $0.9 *$ & $0.9 *$ & $-1.1 *$ & $-0.7 *$ & $-1.1 *$ & $-1.8 *$ & 0.1 \\
\hline AT5G49910 & Chloroplast HSP 70-2 & -0.8 & 1.1 & -0.3 & -0.5 & 0.7 & 0.7 & 0.0 & $-1.4 *$ & $1.9 *$ & $1.9 *$ & $4.3 *$ & 0.5 \\
\hline АT2G28190 & $\mathrm{Cu} / \mathrm{Zn}$ Superoxide dismutase & -0.5 & -0.3 & -0.1 & 0.6 & $1.1 *$ & -0.7 & -0.4 & $-0.8 *$ & 0.2 & 0.1 & 0.2 & 0.0 \\
\hline АТЗG62030 & Cyclophilin Cyp 20-3 & -0.2 & 0.3 & 0.3 & 0.2 & $1.9 *$ & $-0.4 *$ & $0.4 *$ & $-1.0 *$ & $1.7 *$ & 0.2 & $1.6 *$ & -0.2 \\
\hline AT1G19570 & Dehydroascorbate reductase & -0.3 & 1.0 & 0.4 & -0.3 & 1.0 & -0.8 & $-1.2 *$ & $-1.4 *$ & 0.1 & $0.5 *$ & 0.2 & -0.3 \\
\hline AT5G61410 & D-Ribulose-5-P epimerase & -0.3 & 1.0 & 0.5 & -0.2 & ND & ND & ND & ND & $0.3 *$ & 0.2 & $0.4 *$ & 0.0 \\
\hline AT2G21330 & Fructose-bisphosphate aldolase 1 & -0.5 & 1.0 & 0.4 & -0.1 & $1.2 *$ & $0.7 *$ & 0.2 & $-1.7 *$ & $2.0 *$ & $1.2 *$ & $3.4 *$ & 0.2 \\
\hline AT4G38970 & Fructose-bisphosphate aldolase 2 & -1.0 & 1.0 & 0.1 & 0.1 & $1.5 *$ & $1.2 *$ & $2.7 *$ & 0.0 & $1.5 *$ & $0.5 *$ & $2.1 *$ & 0.2 \\
\hline AT1G13440 & GAP C2 subunit & $0.5 *$ & 0.9 & 0.9 & -0.5 & -0.3 & $1.0 *$ & $-1.8 *$ & $-2.5 *$ & 0.1 & 0.2 & $0.4 *$ & 0.1 \\
\hline AT5G20630 & Germin 3 oxalate oxidase & -1.1 & -0.3 & -0.4 & 0.9 & ND & ND & ND & ND & $0.7 *$ & 0.0 & $0.8 *$ & 0.1 \\
\hline AT5G35630 & Glutamine synthetase 2 & -1.2 & 1.0 & 0.0 & $0.3 *$ & $0.4 \quad \star$ & 0.4 & $-0.9 \star$ & $-1.7 *$ & $1.0 *$ & 0.3 & $0.9 *$ & -0.3 \\
\hline AT2G47730 & Glutathione S-transferase F8 & -0.4 & 0.9 & 0.3 & -0.2 & ND & ND & ND & ND & 0.2 & $-0.7 *$ & $-0.7 *$ & -0.3 \\
\hline АT2G30860 & Glutathione S-transferase F9 & -0.2 & 0.7 & 0.1 & -0.4 & $\mathrm{ND}$ & ND & $\mathrm{ND}$ & $\mathrm{ND}$ & $0.6 *$ & 0.2 & $0.9 *$ & 0.1 \\
\hline AT1G42970 & GAPDH B subunit & -0.6 & 1.0 & 0.3 & -0.1 & $1.1 *$ & $-1.2 *$ & -0.5 & $-0.4 *$ & $2.1 *$ & $0.7 *$ & $3.0 *$ & 0.1 \\
\hline AT5G23120 & HCF 136 & -0.8 & 0.3 & 0.3 & $0.7 *$ & $1.1 *$ & $1.3 *$ & 1.8 & -0.7 & $0.6 *$ & -0.1 & 0.2 & -0.2 \\
\hline AT1G53240 & Lactate/malate dehydrogenase & -0.5 & 0.5 & 0.1 & 0.0 & 0.4 & $1.1 *$ & $1.3 *$ & -0.3 & $1.7 *$ & $0.8 *$ & $2.5 *$ & 0.0 \\
\hline АT3G47520 & Malate dehydrogenase, chloro & -0.8 & 0.4 & -0.3 & 0.2 & $-0.7 \star$ & -0.1 & $-0.6 *$ & $0.2 *$ & $0.5 *$ & $0.7 *$ & $1.3 *$ & -0.1 \\
\hline AT3G10920 & Manganese SOD & -0.7 & 0.5 & 0.0 & 0.2 & ND & ND & ND & ND & $0.6 *$ & 0.2 & $0.4 *$ & -0.2 \\
\hline AT2G43750 & O-acetyl serine thiol lyase B & -1.6 & 0.4 & -0.2 & $1.0 *$ & 0.0 & 0.5 & $1.4 \star$ & 0.9 & $0.4 *$ & 0.0 & 0.0 & -0.4 \\
\hline AT1G79550 & Phosphoglycerate kinase 1 & -1.6 & -0.7 & -0.1 & $2.2 *$ & $0.4 *$ & 0.4 & $-2.7 *$ & $-3.5 *$ & $1.0 *$ & $0.5 *$ & $1.6 *$ & -0.1 \\
\hline AT3G08590 & Phosphoglycerate mutase & ND & ND & ND & ND & 0.1 & 0.0 & 0.7 & 0.6 & $1.0 *$ & $0.9 *$ & $2.1 *$ & 0.2 \\
\hline AT1G32060 & Phosphoribulo kinase & -0.7 & 0.7 & -0.1 & -0.1 & 0.4 & 0.4 & $-0.8 *$ & $-1.5 \star$ & $0.7 \star$ & 0.2 & $0.8 *$ & -0.1 \\
\hline AT1G20340 & Plastocyanin (DRT 112) & $-1.2 *$ & 0.7 & -0.4 & 0.1 & ND & ND & ND & ND & $0.7 \star$ & 0.2 & $0.5 *$ & -0.1 \\
\hline AT5G66570 & PSII oxygen evolving complex & -0.3 & 0.1 & 0.7 & 0.9 & 0.2 & -0.3 & $-3.3 *$ & $-3.1 *$ & 0.2 & $-0.4 *$ & $-0.7 *$ & -0.5 \\
\hline AT1G06680 & PSII subunit P-1 & -0.9 & 0.5 & 0.0 & $0.3 *$ & 0.0 & $-0.5 *$ & $-1.0 *$ & -0.5 & $0.4 *$ & -0.2 & -0.2 & -0.3 \\
\hline АТЗG04790 & Ribose 5-phosphate isomerase & $-2.3 *$ & 1.9 & 0.0 & $0.4 *$ & 0.8 & -0.5 & -0.1 & $-0.4 *$ & $1.9 *$ & $0.6 *$ & $2.7 *$ & 0.0 \\
\hline AT5G30510 & Ribosomal protein $\mathrm{S} 1$ & -1.6 & 1.2 & -0.6 & -0.2 & 0.2 & 0.1 & -0.1 & -0.5 & ND & ND & ND & ND \\
\hline АТЗG27830 & RPL12 | ribosomal protein L12-A & -3.0 & 2.4 & -0.9 & -0.3 & 0.5 & -0.6 & -2.1 & -1.9 & ND & ND & ND & ND \\
\hline AT2G39730 & Rubisco activase & -0.3 & 0.6 & 0.4 & 0.1 & 0.3 & 0.2 & $-2.8 *$ & $-3.3 *$ & $0.7 *$ & $0.3 *$ & $1.0 *$ & 0.1 \\
\hline ATCG00490 & RubisCo large subunit & $3.1 *$ & 0.7 & 3.9 & 0.1 & $1.9 *$ & $-0.4 *$ & $-2.0 *$ & $-3.5 *$ & 0.6 & 0.4 & 1.1 & 0.1 \\
\hline AT1G67090 & RubisCO small subunit $1 \mathrm{~A}$ & ND & ND & ND & ND & $1.7 *$ & 0.2 & $-2.5 *$ & $-4.4 *$ & $0.3 *$ & 0.2 & $0.5 *$ & 0.0 \\
\hline AT1G02500 & SAM synthetase 1 & 0.1 & 0.8 & 0.1 & -0.9 & 0.3 & $-0.9 *$ & $-0.8 *$ & -0.1 & -0.2 & $-0.7 *$ & $-1.0 *$ & -0.1 \\
\hline АT3G55800 & Sedoheptulose-bisphosphatase & -1.0 & 0.4 & -0.2 & $0.3 *$ & $-0.5 *$ & $0.7 *$ & -0.3 & -0.5 & $1.8 *$ & $0.7 *$ & $2.4 *$ & 0.0 \\
\hline AT4G08390 & Stromal APx & -0.4 & 1.6 & -0.2 & -1.4 & 1.8 & -0.3 & $2.3 *$ & 0.8 & $0.9 *$ & $1.7 *$ & $3.0 *$ & 0.2 \\
\hline AT1G03680 & Thioredoxin $\mathrm{m} 1$ & -0.8 & 0.7 & -0.2 & -0.2 & 2.3 & $-1.2 *$ & 2.1 & 1.0 & ND & ND & ND & ND \\
\hline AT4G03520 & Thioredoxin m2 & -0.2 & 0.0 & -0.1 & 0.1 & $0.7 *$ & $-1.8 *$ & $-1.7 *$ & -0.6 & 0.3 & -0.2 & 0.0 & 0.0 \\
\hline AT2G21170 & Triose phosphate isomerase & 0.2 & 0.3 & 0.4 & -0.1 & -0.2 & -0.2 & $-0.3 *$ & 0.1 & $0.6 *$ & 0.2 & $0.5 *$ & -0.2 \\
\hline \multicolumn{14}{|c|}{$\mathrm{ND}=$ Not determined } \\
\hline & & & & & & -4.3 & 1 & & 4.2 & & & & \\
\hline \multicolumn{14}{|c|}{$\begin{array}{l}\text { Figure } 5 \text { Comparison of light-dependent changes in spot intensity in silver stained gels, autoradiograms and in transcript levels. } \\
\text { Changes in spot intensities of silver gels and autoradiograms were taken from the three independent experiments similar to Figures } 1,2 \text { and } 3 . \\
\text { Transcript data were extracted from three independent sets of array hybridisation [20]. Changes calculated as value at higher light intensity divided by } \\
\text { intensity at lower light intensity were colour-coded as indicated in the colour bar at the bottom (asterisks indicate significant difference of changes, } \\
\text { t-test ( } p<0.1 \text { for de novo synthesis, } p<0.05 \text { for transcript). }\end{array}$} \\
\hline
\end{tabular}




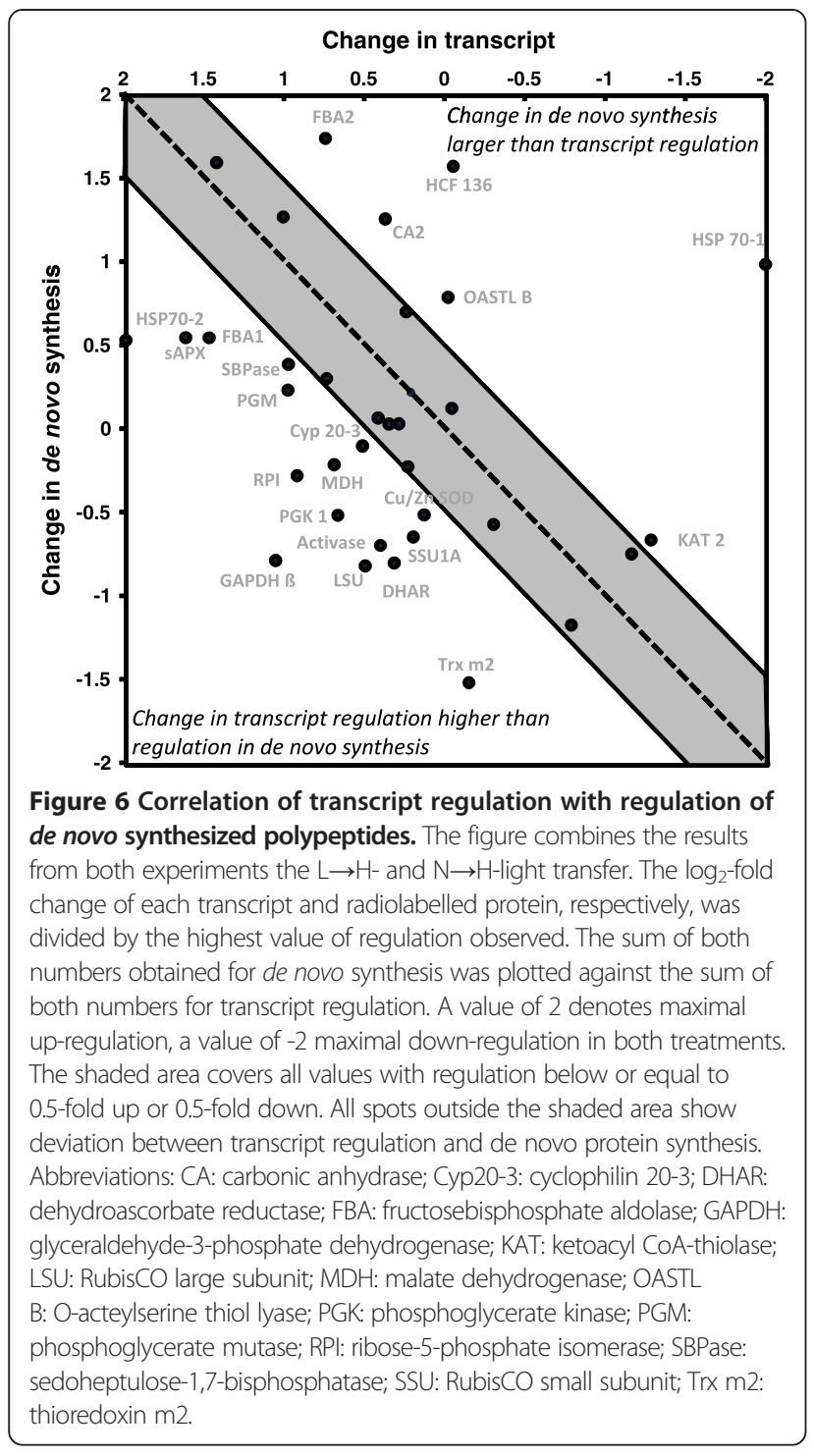

spectrometric analysis, stable isotopes will offer alternative methods to study protein turnover also for eukaryotic multicellular organisms similar to unicellular organisms that can easily be labelled in suspension [32]. A recent review summarizes the strategies to label de novo synthesized proteins by modern proteomics [33]. The here employed method should be added to the portfolio of potential options that can be employed. Starting $4 \mathrm{~h}$ after transfer to $\mathrm{H}$-light appeared suitable because many transcriptional changes had been shown to reach a new steady state at this time, e.g. SAPX [11] or monodehydroascorbate reductase, ABA-dependent cold regulated 47 (COR47), pyruvate kinase related protein (PKRP) [20]. Thus, the labelling that starts after translocation of ${ }^{35} \mathrm{~S}$-methionine through the cuticle to the mesophyll reflects a transcriptional state similar to $6 \mathrm{~h}$ after transfer to $\mathrm{H}$-light for which the transcript analysis has been performed.

\section{Apparent absence of coupling between transcript regulation and de novo protein synthesis}

The comparison of transcript regulation with differences in de novo synthesized protein demonstrates the flexible coupling between transcript regulation and translation (Figure 6). Piques et al. [34] compared transcript levels, ribosome occupancy, enzyme protein amount and activity at different times of day. Their scatter analysis revealed a poor dependency of ribosome loading on total amount of investigated transcripts. The Pearson's correlation coefficient was 0.065 in the dark period and 0.102 in the light period [34]. Here, transcript analysis revealed efficient regulation following transfer to $\mathrm{H}$-light. In sum 27 out of 42 transcripts of identified proteins, i.e. $64 \%$, had $\log _{2}$-fold differences $\geq|0.5|$ between $\mathrm{N}$ - and L-light grown plants prior to $\mathrm{H}$-light treatment. The size of this group of differentially regulated transcripts decreased to only 2 genes after $6 \mathrm{~h}$ of $\mathrm{H}$-light. Thus, transcript regulation within this selected set of identified proteins was entirely in line with the global regulation of the transcriptome after $6 \mathrm{~h}$ of $\mathrm{H}$-light [20]. Thus transcriptional regulation in response to $\mathrm{H}$-light was almost completed after 6 h H-light.

In most cases regulation of transcript amounts was more pronounced than regulation of de novo protein synthesis. Regulation of 6 proteins occurred much stronger at the level of de novo protein synthesis. Several translation factors have been identified as target of posttranslational regulation including thiol-disulfide transitions [35], glutathionylation [36], phosphorylation [37] and S-nitrosylation [38]. Among the targets researchers identified several ribosomal proteins (RPL S1, S6, L13, L30), elongation factors (EF-Tu, EF-G, EF-2, EF-1 $\alpha$ ) and enzymes such as nucleoside diphosphate kinase III and tRNA synthetases which all are involved in translation. Redox changes, ROS production and activation of phosphorylation cascades have been implicated in retrograde signalling. The protein kinases STN7 and STN8 mediate light-dependent reorganization of the photosynthetic apparatus [39]. ROS waves adjust nuclear gene expression in excess light acclimation [40]. ROS and redox feed into the mitogen activated protein kinase pathway [41]. Translational activity is strongly altered by ROS in yeast [42]. Thus, translation in plants is a prime but hitherto not sufficiently explored target of retrograde signalling as underlined by the data presented in this paper. The reader is also referred to the metaanalysis by Schwarzländer et al. [43] who observed that transcripts encoding for proteins involved in protein synthesis are significantly affected by retrograde signals released from the mitochondrion.

\section{Functional implications of translational control of identified targets}

Control of posttranscriptional processes accelerates the speed and versatility of stress acclimation. The high 
significance of specific transcript recruitment to ribosomes in plants has best been demonstrated for acclimation to hypoxia [44]. The authors showed hypoxia-specific changes of transcriptome and translatome at the global, organ- and cell-specific level. Preferential ribosome association was observed for sucrose transporters, heat shock factors and transcription factors [45]. Here, expression of six genes was more strongly regulated at the level of protein synthesis than of transcript accumulation. It may be assumed that the gene product functions are needed after transfer to $\mathrm{H}$-light. Despite down-regulation at the transcript level, ${ }^{35} \mathrm{~S}$-methionine incorporation into HSP70-1 still occurred at high rates. In a converse manner, HSP702 was synthesized at similar rates despite a large increase in transcript amount. Chloroplast HSP70s facilitate protein import into the chloroplasts, a function which is of eminent importance during environmental transition such as exposure to excess excitation energy [45]. High chlorophyll fluorescence HCF136 was identified in a screen for genes with function in assembly of functional photosystem II [46]. FBP aldolase as part of the Calvin cycle, O-acetyl serine thiol lyase with its function in cysteine synthesis, carbonic anhydrase which facilitates equilibration between carbonate and $\mathrm{CO}_{2}$ as substrate of the Calvin cycle and 3-ketoacyl CoA thiolase 3 involved in fatty acid synthesis showed stimulated de novo synthesis. This type of regulation may easily be reconciled with their metabolic functions which are important for $\mathrm{H}$-light acclimation. Arguments appear less straight forward when it comes to explain the low level of de novo protein synthesis observed for 16 genes. They mostly function in metabolism such as seduheptulose-1,7-bisphosphatase which is suggested to limit Calvin cycle activity [47], large and small subunits of RubisCO, RubisCO activase, phosphoglycerate mutase, phosphoglycerate kinase and ribose-5-phosphate isomerase. Others are involved in redox homeostasis and antioxidant defence (malate dehydrogenase, dehydroascorbate reductase, superoxide dismutase, stromal ascorbate peroxidase and the regulator of chloroplast cysteine synthase complex cyclophilin Cyp20-3 [12]. It may be hypothesized that these proteins are present at sufficient amounts prior to H-light treatment and that the low ratio of de novo synthesis-to-transcript amount merely reflects such mechanisms of yet un-understood feedback control. It should be noted that photoreceptor-dependent signaling might contribute to the transcriptional and translational responses described in this paper, albeit previous work largely excluded a major role of photoreceptors in this particular experimental setup $[7,11]$.

\section{Conclusions}

Translational control is still poorly investigated particularly in plants: Initiation, elongation and pausing contribute to transcript selection and efficiency of translation.
De novo labelling as used here determines the outcome of all these processes and, therefore is a better readout of protein synthesis than ribosome loading eventually combined with ribosome footprinting [48]. The latter technique allows for profiling of RNA sequences by deep sequencing that are protected from degradation by associated ribosomes. Our study adds a novel method to the portfolio available to investigate posttranscriptional regulation. The results show that $\mathrm{H}$-light acclimation involves translational control as decisive part of retrograde signalling and concerns a large fraction, namely almost $2 / 3$ in the set of identified proteins. Furthermore the rate of $d e$ novo protein synthesis cannot directly be predicted from transcript levels.

\section{Methods}

\section{Plant growth and treatment}

Arabidopsis thaliana was grown in a growth chamber in a mix of 50\% soil, 25\% Perlite and 25\% Vermiculite, supplemented with one dose of Lizetan (Bayer, Germany). Following seed stratification for $2 \mathrm{~d}$ at $4{ }^{\circ} \mathrm{C}$, plants were grown for $30 \mathrm{~d}$ in $80 \mu \mathrm{mol}$ quanta $\mathrm{s}^{-1} \mathrm{~m}^{-2}$ (N-light) with a $14 \mathrm{~h}$ light and $10 \mathrm{~h}$ dark phase. Subsequently, plants were transferred to $8 \mu \mathrm{mol} \cdot \mathrm{s}^{-1} \cdot \mathrm{m}^{-2}$ (L-light) for $10 \mathrm{~d}$ prior to the experiment with transfer to $800 \mu \mathrm{mol} \cdot \mathrm{s}^{-1} \mathrm{~m}^{-2}$ (H-light; 100-fold light increase). The L-plants have been shown to be entirely shade acclimated [11]. Another set of plants was grown in $\mathrm{N}$-light for the whole period of $40 \mathrm{~d}$ and also transferred to $800 \mu \mathrm{mol} \mathrm{s}^{-1} \mathrm{~m}^{-2}$ (10-fold light increase). Control plants were kept in L- and N-light, respectively, and harvested in parallel to the $\mathrm{H}$-light rosettes. Harvest time was always at $3 \mathrm{pm}$. Chlorophyll, protein and RNA contents and effective quantum yield of photosystem II by pulse amplitude modulation (PAM) were determined as described in Oelze et al. [11].

\section{In vivo labelling of de novo synthesized proteins} L- $\left[{ }^{35} \mathrm{~S}\right]$-methionine (NEG009T, Perkin Elmer, MA, USA) was supplemented with $0.1 \%(\mathrm{v} / \mathrm{v})$ Triton $\mathrm{X}-100$ and applied to leaf surfaces with a radioactivity of $20 \mu \mathrm{Ci}$ per leaf. For each treatment $20 \mu \mathrm{Ci}$ were administered to fully expanded leaves from three different rosettes $4 \mathrm{~h}$ after transfer to H-light. After $6 \mathrm{~h}$, the leaves were excised from the rosettes, washed first with $0.1 \%(\mathrm{v} / \mathrm{v})$ Triton X-100 and then with $0.5 \mathrm{~mol} / \mathrm{L}$ Tris- $\mathrm{Cl}, \mathrm{pH} 6.8$.

\section{D-gel electrophoresis}

Leaves were ground with a pestle in $1 \mathrm{~mL}$ acetone/ trichloroacetic acid/ $\beta$-mercaptoethanol (89.93:10:0.07\% v/v) according to Méchin et al. [49]. Following precipitation at $-20^{\circ} \mathrm{C}$ for at least $1 \mathrm{~h}$ and subsequent centrifugation, the pellet was washed and sedimented thrice with ice-cold acetone/ $\beta$-mercaptoethanol, dried and resuspended in lysis buffer [50]. For radioactive samples, incorporated ${ }^{35} \mathrm{~S}$ 
was quantified by precipitating aliquots on Whatman filter followed by scintillation counting. For silver-stained gels, protein amounts were quantified at $595 \mathrm{~nm}$ with the BioRad protein assay. Separation in the first dimension was achieved with Immobiline ${ }^{\mathrm{Tm}}$ DryStrips $(\mathrm{pH}$ range 3-10 NL, $18 \mathrm{~cm}$, GE Healthcare, Uppsala, Sweden). Sample equivalent to $100 \mu \mathrm{g}$ protein or $10^{6} \mathrm{cpm}$ was dissolved in $340 \mu \mathrm{L}$ complete rehydration buffer $(8 \mathrm{~mol} / \mathrm{L}$ urea, $2 \%(\mathrm{w} / \mathrm{v})$ CHAPS, 0.002 bromophenolblue, 0.3\% ampholyte, $1.4 \%$ (w/v) dithiothreitol) and applied to the Immobiline strips. The rehydration and isoelectric focusing protocol consisted of the steps as follows: $1 \mathrm{~h} 0 \mathrm{~V}, 12 \mathrm{~h} 30 \mathrm{~V}, 2 \mathrm{~h} 60 \mathrm{~V}, 1 \mathrm{~h}$ $500 \mathrm{~V}, 1 \mathrm{~h} 1000 \mathrm{~V}, 1000-8000 \mathrm{~V}$ for variable time to reach 42000 Vh. Separation in the second dimension was performed on a $12 \%(\mathrm{w} / \mathrm{v})$ SDS-PAGE of $18 \mathrm{~cm}$ length at $40 \mathrm{~mA}$. Silver staining was performed according to Blum et al. [51] and autoradiography as described in Dietz and Bogorad [52].

\section{Analysis of 2D-gels and heat map construction}

Delta 2D software (Decodon, Greifswald, Germany) with its SmartVectors Technology was used to align the gel images to each other to allow for efficient and reliable spot matching. A fusion image was generated containing all spot positions. Each gel was matched with this master gel. Spot boundary detection, pixel intensity quantification and statistical analysis (one way ANOVA) were performed with the built in TIGR MeV tool. Before constructing the heat map, the data set was standardized to zero mean and unit variance. Clustering was achieved using the eucledian distance and complete linkage- default settings of the delta 2D software (DECODON, Greifswald, Germany).

\section{ATH1-genome array hybridisation and analysis}

Isolated total RNA was sent to KFB-company (Competence Centre for Fluorescence Bioanalytics, Regensburg, Germany), processed, and derived fluorescent probes hybridized against the 25mer oligonucleotide ATH1-genome array (Affimetrix, Santa Clara, USA). Glyceraldehyde-3phosphate dehydrogenase, actin and ubiquitin were used as reference transcripts. The raw data were fed into ROBIN (MPI Golm, Germany). Statistical evaluation of the data was based on the corrected p-value [22,23].

\section{Protein identification by mass spectrometry}

Corresponding areas of interest were excised from the 2D gels and washed with (a) two times a solution containing trifluoroacetic acid $(0.1 \% \mathrm{w} / \mathrm{v})$ and acetonitrile $(60 \% \mathrm{v} / \mathrm{v})$, (b) acetonitrile (50\%), (c) acetonitrile (50\%)/50 $\mathrm{mM} \mathrm{NH}_{4}$ $\mathrm{HCO}_{3}$ for $0.5 \mathrm{~h}$, and (d) acetonitrile (50\%)/10 mM NH $\mathrm{HCO}_{3}$ at $21^{\circ} \mathrm{C}$ for $0.5 \mathrm{~h}$ each. Dried gel slices were resuspended in trypsin solution $(0.013 \mathrm{mg}$ sequencing quality trypsin (Promega, Mannheim, Germany) in $10 \mathrm{mM} \mathrm{NH}_{4}$ $\mathrm{HCO}_{3} \mathrm{pH} 8.0$ ) at $4^{\circ} \mathrm{C}$ for $0.5 \mathrm{~h}$ and afterwards at $37^{\circ} \mathrm{C}$ for about 15 h. Digestion solutions were supplemented with cyano-4-hydroxy-cinnamic acid at a $60: 40 \%$ ratio. Mass spectra were determined using a Biflex III matrix-assisted laser desorption/ionisation-time of flight mass spectrometer (MALDI-TOF)-MS (Bruker, Bremen, Germany) (previously described [53]). The peptide mass fingerprints (PMF) obtained by tryptic digested proteins were analyzed by MALDI-TOF-MS and proteins were identified by MASCOT (Multiple-Access Space-Time Coding Testbed) software and the National Center for Biotechnology Information (NCBI) protein database. The program compares the peptide masses obtained from experimental digestion to the predicted peptide masses from the theoretical digestion of proteins.

\section{Correlation of de novo protein synthesis and transcript regulation during $\mathrm{H}$-light treatment}

The obtained values of the spot intensities for the autoradiograms by Delta $2 \mathrm{D}$ were used to calculate the ratios between the different treatments $(\mathrm{N} / \mathrm{L}, \mathrm{N} \rightarrow \mathrm{H}, \mathrm{L} \rightarrow \mathrm{H}$, $\mathrm{L} \rightarrow \mathrm{H} / \mathrm{N} \rightarrow \mathrm{H}$ ). The ratios were recalculated as $\log _{2}$-fold change values, to be easily comparable to the obtained $\log _{2}$-fold change values of the microarray experiments by ROBIN.

For the comparison of de novo protein synthesis and transcriptional regulation the maximum reactions (up or down regulation) for both $\mathrm{H}$-light treatments $(\mathrm{L} \rightarrow \mathrm{H}$, $\mathrm{N} \rightarrow \mathrm{H})$ were used as reference. Each value $\left(\mathrm{F}_{\mathrm{POI}}\right)$ of the different targets was divided by the appropriate maximum reaction $\left(\mathrm{F}_{\mathrm{Ext}}\right.$ i up-regulation was divided by maximum positive reaction while down regulated targets were divided by the maximal negative reaction) for each treatment $(\mathrm{N} \rightarrow \mathrm{H}$ or $\mathrm{L} \rightarrow \mathrm{H})$ and for both methods (de novo protein synthesis or transcript regulation). Afterwards the calculated values for both de novo protein synthesis reactions $(\mathrm{N} \rightarrow \mathrm{H}$ or $\mathrm{L} \rightarrow \mathrm{H}$ light shift) or for both transcriptional regulations were summed up to give the response factor R.

$$
R=\frac{F_{L \rightarrow H(P O I)}}{F_{L \rightarrow H(E x t)}}+\frac{F_{N \rightarrow H(P O I)}}{F_{N \rightarrow H(E x t)}}
$$

Therefore, the maxima of regulation would fit in the range between -2 and 2 . To evaluate the relationship between de novo synthesis and transcriptional regulation, the calculated values were plotted in a diagram where deviation from the diagonal $\leq 0.5$ was set as a cutoff (gray shaded area) and only larger deviations (outside this area) were accepted to indicate distinct regulation between transcript and de novo protein synthesis.

\section{Abbreviations}

2D: Two dimensional; ABA: Abscisic acid; ABI: ABA insensitive; GUN: Genome uncoupled; H: High light; L: Low light; MS: Mass spectrometry; N: Normal light; PAGE: Polyacrylamide gel electrophoresis; PQ: Plastoquinone; 
ROS: Reactive oxygen species; RubisCO: Ribulose-1,5-bisphosphate carboxylase oxygenase.

\section{Competing interests}

The authors declare that they have no competing interests.

\section{Authors' contributions}

MLO, MM, MOV: Experimental acquisition, analysis and interpretation of data, KJD: Design and discussion of study and writing paper. All authors read and approved the final manuscript.

\section{Acknowledgements}

This work was conducted within FOR 804, SPP1710 and project DI 346. MLO acknowledges support by the NRW International Graduate School on Bioinformatics and Genome Research. Authors also thank Dr. Peter Klein for his discussion in computational work.

Received: 24 January 2014 Accepted: 24 April 2014

Published: 30 April 2014

\section{References}

1. Dietz KJ, Pfannschmidt T: Novel regulators in photosynthetic redox control of plant metabolism and gene expression. Plant Physiol 2011, 155:1477-1485.

2. Wobbe L, Blifernez O, Schwarz C, Mussgnug JH, Nickelsen J, Kruse O: Cysteine modification of a specific repressor protein controls the translational status of nucleus-encoded LHCII mRNAs in Chlamydomonas. Proc Natl Acad Sci U S A 2009, 106:13290-13295.

3. Baena-Gonzalez E: Energy signaling in the regulation of gene expression during stress. Mol Plant 2010, 3:300-313.

4. Narsai R, Howell KA, Millar AH, O'Toole N, Small I, Whelan J: Genome-wide analysis of mRNA decay rates and their determinants in Arabidopsis thaliana. Plant Cell 2007, 19:3418-3436.

5. Olinares PD, Ponnala L, van Wijk KJ: Megadalton complexes in the chloroplast stroma of Arabidopsis thaliana characterized by size exclusion chromatography, mass spectrometry, and hierarchical clustering. Mol Cell Proteomics 2010, 9:1594-1615.

6. Escoubas JM, Lomas M, LaRoche J, Falkowski PG: Light intensity regulation of cab gene transcription is signaled by the redox state of the plastoquinone pool. Proc Natl Acad Sci U S A 1995, 92:10237-10241.

7. Fey V, Wagner R, Bräutigam K, Wirtz M, Hell R, Dietzmann A, Leister D, Oelmüller R, Pfannschmidt T: Retrograde plastid redox signals in the expression of nuclear genes for chloroplast proteins of Arabidopsis thaliana. J Biol Chem 2005, 280:5318-5328.

8. Bonardi V, Pesaresi P, Becker T, Schleiff E, Wagner R, Pfannschmidt T, Jahns $P$, Leister D: Photosystem II core phosphorylation and photosynthetic acclimation require two different protein kinases. Nature 2005, 437:1179-1182.

9. Baier M, Ströher E, Dietz KJ: The acceptor availability at photosystem I and ABA control nuclear expression of 2-Cys peroxiredoxin-A in Arabidopsis thaliana. Plant Cell Physiol 2004, 45:997-1006.

10. Galvez-Valdivieso G, Fryer MJ, Lawson T, Slattery K, Truman W, Smirnoff N, Asami T, Davies WJ, Jones AM, Baker NR, Mullineaux PM: The high light response in Arabidopsis involves $A B A$ signaling between vascular and bundle sheath cells. Plant Cell 2009, 21:2143-2162.

11. Oelze ML, Vogel MO, Alsharafa K, Kahmann U, Viehhauser A, Maurino VG, Dietz KJ: Efficient acclimation of the chloroplast antioxidant defence of Arabidopsis thaliana leaves in response to a 10 - or 100 -fold light increment and the possible involvement of retrograde signals. J Exp Bot 2012, 63:1297-1313.

12. Park SW, Li W, Viehhauser A, He B, Kim S, Nilsson AK, Andersson MX, Kittle JD, Ambavaram MM, Luan S, Eske AR, Tholl D, Cimini D, Ellerström M, Coaker G, Mitchell TK, Pereira A, Dietz KJ, Lawrence CB: Cyclophilin 20-3 relays a 12-oxo-phytodienoic acid signal during stress responsive regulation of cellular redox homeostasis. Proc Natl Acad Sci U S A 2013, 110:9559-9564.

13. Koussevitzky S, Nott A, Mockler TC, Hong F, Sachetto-Martins G, Surpin M, Lim J, Mittler R, Chory J: Signals from chloroplasts converge to regulate nuclear gene expression. Science 2007, 316:715-719.

14. Lee KP, Kim C, Landgraf F, Apel K: EXECUTER1- and EXECUTER2-dependent transfer of stress-related signals from the plastid to the nucleus of Arabidopsis thaliana. Proc Natl Acad Sci U S A 2007, 104:10270-10275.
15. Eibl C, Zou ZR, Beck A, Kim M, Mullet J, Koop HU: In vivo analysis of plastid psbA, rbcL and rpl32 UTR elements by chloroplast transformation: tobacco plastid gene expression is controlled by modulation of transcript levels and translation efficiency. Plant J 1999, 19:333-345.

16. Hartwell J, Jenkins GI, Wilkins MB, Nimmo HG: The light induction of maize phosphoenolpyruvate carboxylase kinase translatable mRNA requires transcription but not translation. Plant Cell Environ 1999, 22:883-889.

17. Bindschedler LV, Cramer R: Quantitative plant proteomics. Proteomics 2011, 11:756-775

18. Blinda A, Koch B, Ramanjulu S, Dietz KJ: De novo synthesis and accumulation of apoplastic proteins in leaves of heavy metal-exposed barley seedlings. Plant Cell Environ 1997, 20:969-981.

19. Hinkson IV, Elias JE: The dynamic state of protein turnover: it's about time. Trends Cell Biol 2011, 21:293-303.

20. Alsharafa K, Vogel MO, Oelze ML, Moore M, Stingl N, König K, Friedman H, Mueller MJ, Dietz KJ: Kinetics of retrograde signalling initiation in the high light response of Arabidopsis thaliana. Philos Trans R Soc Lond B Biol Sci, in press.

21. Irizarry RA, Bolstad BM, Collin F, Cope LM, Hobbs B, Speed TP: Summaries of Affimetrix Gene Chip probe level data. Nucleic Acids Res 2003, 31:e15.

22. Benjamini $Y$, Hochberg Y: Controlling the false discovery rate. A practical and powerful approach to multiple testing. J R Stat Soc B 1995, 57:289-300

23. Benjamini $Y$, Hochberg $Y$ : On the adaptive control of the false discovery rate in multiple testing with independent statistics. J Educ Behav Stat 2000, 25:60-83.

24. Boardman NK: Comparative photosynthesis of sun and shade plants. Annu Rev Plant Physiol 1977, 28:355-377.

25. Li Z, Wakao S, Fischer BB, Niyogi KK: Sensing and responding to excess light. Annu Rev Plant Biol 2009, 60:239-260.

26. Winter $\mathrm{H}$, Robinson DG, Heldt HW: Subcellular volumes and metabolite concentrations in spinach leaves. Planta 1994, 193:530-535.

27. Dietz KJ, Heilos L: Carbon metabolism in spinach leaves as affected by leaf age and phosphorus and sulfur nutrition. Plant Physiol 1990, 93:1219-1225

28. Leong TY, Anderson JM: Adaptation of the thylakoid membranes of pea chloroplasts to light intensities. II. Regulation of electron transport capacities, electron carriers, coupling factor $\left(\mathrm{CF}_{1}\right)$ activity and rates of photosynthesis. Photosynthesis Res 1984, 5:117-128.

29. Hikosaka K, Terahima I: A model of the acclimation of photosynthesis in the leaves of C-3 plants to sun and shade with respect to nitrogen use. Plant Cell Environ 1995, 18:605-618.

30. Hahn A, Kilian J, Mohrholz A, Ladwig F, Peschke F, Dautel R, Harter K, Berendzen KW, Wanke D: Plant core environmental stress response genes are systemically coordinated during abiotic stresses. Int J Mol Sci 2013, 14:7617-7641.

31. Sun JD, Nishio JN, Vogelmann TC: S-35-methionine incorporates differentially into polypeptides across leaves of spinach (Spinacia oleracea). Plant Cell Physiol 1996, 37:996-1006.

32. Trotschel C, Albaum SP, Poetsch A: Proteome turnover in bacteria: current status for Corynebacterium glutamicum and related bacteria. Microbial Biotech 2013, 6:708-719.

33. Nelson CJ, Li L, Millar AH: Quantitative analysis of protein turnover in plants. Proteomics 2014, 14:579-592.

34. Piques M, Schulze WX, Höhne M, Usadel B, Gibon Y, Rohwer J, Stitt M: Ribosome and transcript copy numbers, polysome occupancy and enzyme dynamics in Arabidopsis. Mol Syst Biol 2009, 5:314.

35. Balmer $Y$, Koller A, del Val G, Manieri W, Schürmann P, Buchanan BB: Proteomics gives insight into the regulatory function of chloroplast thioredoxins. Proc Natl Acad Sci U S A 2003, 100:370-375.

36. Rouhier N, Villarejo A, Srivastava M, Gelhaye E, Keech O, Droux M, Finkemeier I, Samuelsson G, Dietz KJ, Jacquot JP, Wingsle G: Identification of plant glutaredoxin targets. Antioxid Redox Signal 2005, 7:919-929.

37. van Bentem SD, Anrather D, Dohnal I, Roitinger E, Csaszar E, Joore J, Buijnink J, Carreri A, Forzani C, Lorkovic ZJ, Barta A, Lecourieux D, Verhounig A, Jonak C, Hirt HJ: Site-specific phosphorylation profiling of Arabidopsis proteins by mass spectrometry and peptide chip analysis. Proteome Res 2008, 7:2458-2470.

38. Lindermayr C, Saalbach G, Durner J: Proteomic identification of S-nitrosylated proteins in Arabidopsis. Plant Physiol 2005, 137:921-930. 
39. Herbstová M, Tietz S, Kinzel C, Turkina MV, Kirchhoff H: Architectural switch in plant photosynthetic membranes induced by light stress. Proc Natl Acad Sci U S A 2012, 109:20130-20135.

40. Galvez-Valdivieso G, Mullineaux PM: The role of reactive oxygen species in signalling from chloroplasts to the nucleus. Physiol Plant 2010, 138:430-439.

41. Pitzschke A, Hirt H: Disentangling the complexity of mitogen-activated protein kinases and reactive oxygen species signaling. Plant Physiol 2009, 149:606-615.

42. Grant CM: Regulation of translation by hydrogen peroxide. Antioxid Redox Signal 2011, 15:191-203.

43. Schwarzländer M, König AC, Sweetlove L, Finkemeier I: The impact of impaired mitochondrial function on retrograde signalling: a meta-analysis of transcriptomic responses. J Exp Bot 2012, 63:1735-1750.

44. Mustroph A, Zanetti ME, Jang CJ, Holtan HE, Repetti PP, Galbraith DW, Girke T, Bailey-Serres J: Profiling translatomes of discrete cell populations resolv.es altered cellular priorities during hypoxia in Arabidopsis. Proc Natl Acad SCi USA 2009, 106:18843-18848.

45. Latijnhouwers M, Xu XM, Møller SG: Arabidopsis stromal 70-kDa heat shock proteins are essential for chloroplast development. Planta 2010 232:567-578.

46. Meurer J, Plücken H, Kowallik KV, Westhoff P: A nuclear-encoded protein of prokaryotic origin is essential for the stability of photosystem II in Arabidopsis thaliana. EMBO J 1998, 17:5286-5297.

47. Lefebvre S, Lawson T, Zakhleniuk OV, Lloyd JC, Raines CA, Fryer M: Increased sedoheptulose-1,7-bisphosphatase activity in transgenic tobacco plants stimulates photosynthesis and growth from an early stage in development. Plant Physiol 2005, 138:451-460.

48. Ingolia NT, Ghaemmaghami S, Newman JR, Weissman JS: Genome-wide analysis in vivo of translation with nucleotide resolution using ribosome profiling. Science 2009, 324:218-223.

49. Méchin V, Damerval C, Zivy M: Total protein extraction with TCA acetone. Methods Mol Biol 2007, 355:1-8.

50. Méchin V, Consoli L, Le Guilloux M, Damerval C: An efficient solubilízation buffer for plant proteins focused in immobilized pH gradients. Proteomics 2003, 3:1299-1302

51. Blum H, Beier H, Gross HJ: Improved silver staining of plant proteins, RNA and DNA in polyacrylamide gels. Electrophoresis 1987, 8:93-99.

52. Dietz K, Bogorad L: Plastid development in Pisum sativum leaves during greening: I. A Comparison of plastid polypeptide composition and in organello translation characteristics. Plant Physiol 1987, 85:808-815.

53. Ströher E, Dietz KJ: The dynamic thiol-disulphide redox proteome of the Arabidopsis thaliana chloroplast as revealed by differential electrophoretic mobility. Physiol Plant 2008, 133:566-583.

doi:10.1186/1471-2164-15-320

Cite this article as: Oelze et al: : The link between transcript regulation and de novo protein synthesis in the retrograde high light acclimation response of Arabidopsis thaliana. BMC Genomics 2014 15:320

\section{Submit your next manuscript to BioMed Central and take full advantage of:}

- Convenient online submission

- Thorough peer review

- No space constraints or color figure charges

- Immediate publication on acceptance

- Inclusion in PubMed, CAS, Scopus and Google Scholar

- Research which is freely available for redistribution 